\title{
Implementation of a Student Learning Assistant (SLA) scheme on a new higher education campus
}

\author{
B.K. Ashley Hoolash \\ Middlesex University, Mauritius Branch Campus, UK \\ Adeelah Kodabux \\ Middlesex University, Mauritius Branch Campus, UK
}

\begin{abstract}
Middlesex University, Mauritius Branch Campus, was setup in 2010 and, as any credible British higher education institution, its aim has been to improve students' learning as well as students' experience. One such venture has been the creation of the Student Learning Assistant (SLA) scheme. The pilot project was run from January 2013 to May 2013 and the scheme is ongoing for the new academic year, which started in September 2013. The purpose of this reflective paper is to explain thoroughly the implementation process of the SLA scheme and to recommend any improvements that can be instigated to overcome the challenges that the authors (SLA coordinators) faced when overseeing the running of the SLA scheme.
\end{abstract}

Keywords: SLA; higher education; peer learning; students; lecturers.

\section{Introduction}

The Student Learning Assistant (SLA) scheme is a new project at Middlesex University, Mauritius Branch Campus (MUMBC). MUMBC is a mirror image of the mother campus in London (Hendon Campus) in terms of the quality of education provided. One of its priorities is to offer the same services to the students on the Mauritius campus as in London. As a result of this objective, the authors of this paper have taken the responsibility to ensure the provision and sustainability of the SLA support. 
The SLA venture is comparable to initiatives at other universities where it is generally dubbed as Peer Assisted Learning (PAL) in the United States (US) or as Peer Assisted Study Sessions (PASS) in Australia and New Zealand. It draws from the Supplemental Instruction (SI) model, which was introduced in 1973 at the University of Missouri-Kansas City as an academic assistance mechanism to improve first year students' performance (Arendale, 1994). The SI programme has been widely implemented in higher education institutions, notably in the US where the Department of Education has acknowledged its success (Van der Meer and Scott, 2009) and in Australia and New Zealand where it has been comprehensively expanded since the 1970s (Loh, 1993; Barrett et al., 1994; Ahrens et al., 1996; Beasley, 1997).

Similar to the process of PAL, whereby 'people from similar social groupings who are not professional teachers help each other to learn and learn themselves by teaching' (Ibrahim and Aaijaz, 2011, p.93), the SLA scheme at MUMBC constitutes a framework of studentto-student support to motivate student engagement and ultimately create an effective learning environment within the classroom. The SLAs are either second or third year undergraduate students who have already successfully completed a module in their previous academic year. They are identified by academics as ideal candidates who can provide an additional support during non-teaching classroom settings. The SLAs' candidacy is gauged upon their educational achievements and other remarkable study or transferable skills, which they have showcased as students. Following their selection, they are then trained to work with groups of students and also mentored on how to cope with different scenarios that they may come across in a class setting.

This paper is a reflection of the experiment of the SLA scheme on a new higher education campus. It begins with a rationale explaining its importance and reasons behind its implementation. To gauge the benefits and challenges of the pilot venture at MUMBC, an action research design was conducted. The subsequent sections elaborate thoroughly on the SLA's implementation structure and finally make recommendations to avoid the obstacles the SLA coordinators initially faced when overseeing the smooth running of the project. 


\section{Rationale for the SLA scheme's implementation on a new higher education campus}

In higher education, and especially on a new international campus such as MUMBC, the importance of the SLA scheme is becoming increasingly tangible both for the students receiving the support and the SLAs themselves, as is evidenced by research on peertutoring (Stout and McDaniel, 2006; Galbraith and Winterbottom, 2011). Boud et al. (2001) argue that the academic transition from secondary education to higher education, which is less structured and involves independent learning, often tends to be a challenge for some new students and even more so in larger classes. As an international campus, which welcomes students from diverse educational backgrounds, MUMBC has to take into consideration the different schools of thought of the joining students, especially if for some disciplines top-up students are able to join in the second or third year (top-up students are those students joining in either year two or year three, having previous academic qualifications which entitled them to exemptions of modules taught in year one or year two). In fact, Lillis (2001) highlights that for many students especially those from nontraditional contexts - that is, those from different educational, cultural and socio-economic backgrounds - the academic practices of higher education disciplines may appear alienating. The academic transition for such students involves some socio-cultural factors that would affect the successful implementation of learning development strategies. In his book Leaving College (1987), Tinto establishes a clear relationship between students' retention over different periods of time and the environment they are operating in. The environment, in this case, refers to the institution's academic and social organisations and the individuals responsible for shaping those organisations. Tinto's argument highlights the key importance played by the interaction between members of the institution and new students going through the stages of transition that mark their first year.

A review of learning and teaching methods, which attempts to overcome the challenges in boosting student engagement with learning, is encouraged (Boud et al., 2001). In order to support the transition to first year of university, the strategy of simply adding programmes 'around the curriculum, or in aid of it' (Kift, 2009, p.1) is not sufficient. Student engagement must be embedded in the first year curriculum so as to make students realise their sense of belonging to the university and to the programme they are studying. According to Kift (2009, p.3), the obvious way to sustain increased participation and diversity is 'through coherent, intentional, supportive and inclusive first year curriculum Journal of Learning Development in Higher Education, Issue 7: June 2014 
design'. To this effect, the Australasian Survey of Student Engagement (AUSSE) provides an effective means of measuring students' participation in higher education. Such crossnational perspectives drawing from Australia, New Zealand and the US are highly valuable to MUMBC particularly because they mirror the global context in which the higher education industry operates. The cross-national collection of data provides an incentive for guiding new thinking about good student engagement practice. For example, a key lesson for MUMBC to retain from AUSSE (2010) and to use as a justification for its SLA implementation is that, albeit students are seen to be responsible for constructing their knowledge, learning equally depends on the institution and staff responsible for creating conditions that promote student engagement (Kuh, 2003; Kuh, 2008).

The rationale for the implementation of the SLA scheme is further strengthened by the feedback received from students who benefited from the SLA support. The feedback analysis demonstrates that the implementation of the SLA scheme has been received as a positive contribution to learning development strategies at MUMBC. As a point of illustration, the comments recorded from the students on the questionnaire reported the following testimonials and indicated a growing correlation between the SLA's role and students' incentive and their comfort to engage in the classroom:

The SLA makes me feel comfortable to ask any questions or queries. As the SLA is also a student, she is in a better place to know where the particular problem is and also give her experience on how she solved it to have better grades.

The SLA helps us being more at ease with the subject because we feel more comfortable asking about the things that we haven't understood rather than the lecturer to whom we might hesitate to ask questions.

The SLA facilitates the learning process and gives useful advice as to how to approach the course. 
Whenever she is being asked a question, she makes her best to answer it and the wonderful thing is that she shares her experience with us, which will enable us to prevent making mistakes and approach the module in a positive way.

Judging from the above comments on students' experience of the SLA's role, the SLA scheme can be viewed as a useful strategy to improve student learning, experience and support. The common experiences shared by the students can be summarised in terms of the SLA's familiarity with the topic, enabling a clarity of thought for the modules and facilitating their comprehension of the topic. In this context, SLAs act as powerful role models who assist in developing a 'safe' learning environment. In addition to the skills they share with the students, the latter feel comfortable to consult SLAs because they share their recently acquired knowledge and personal experience of having studied the same module. Hence, the benefits gained from consulting the SLAs are in lowering personal distress they may face when going through unfamiliar concepts from the course, and increasing the feeling of satisfaction with the overall module owing to a mutual support system which has been developed in the class by the SLAs (Parr and Townsend, 2002; Glynn et al., 2006).

The following sections proceed to elaborate on the SLA support organisation structure in place at MUMBC, which is concisely illustrated in Figure 1. 
Figure 1. SLA scheme implementation structure.

Phase 1

Phase 2

SLA coordinators contact the academic staff and organise workshops to inform them of the SLA scheme

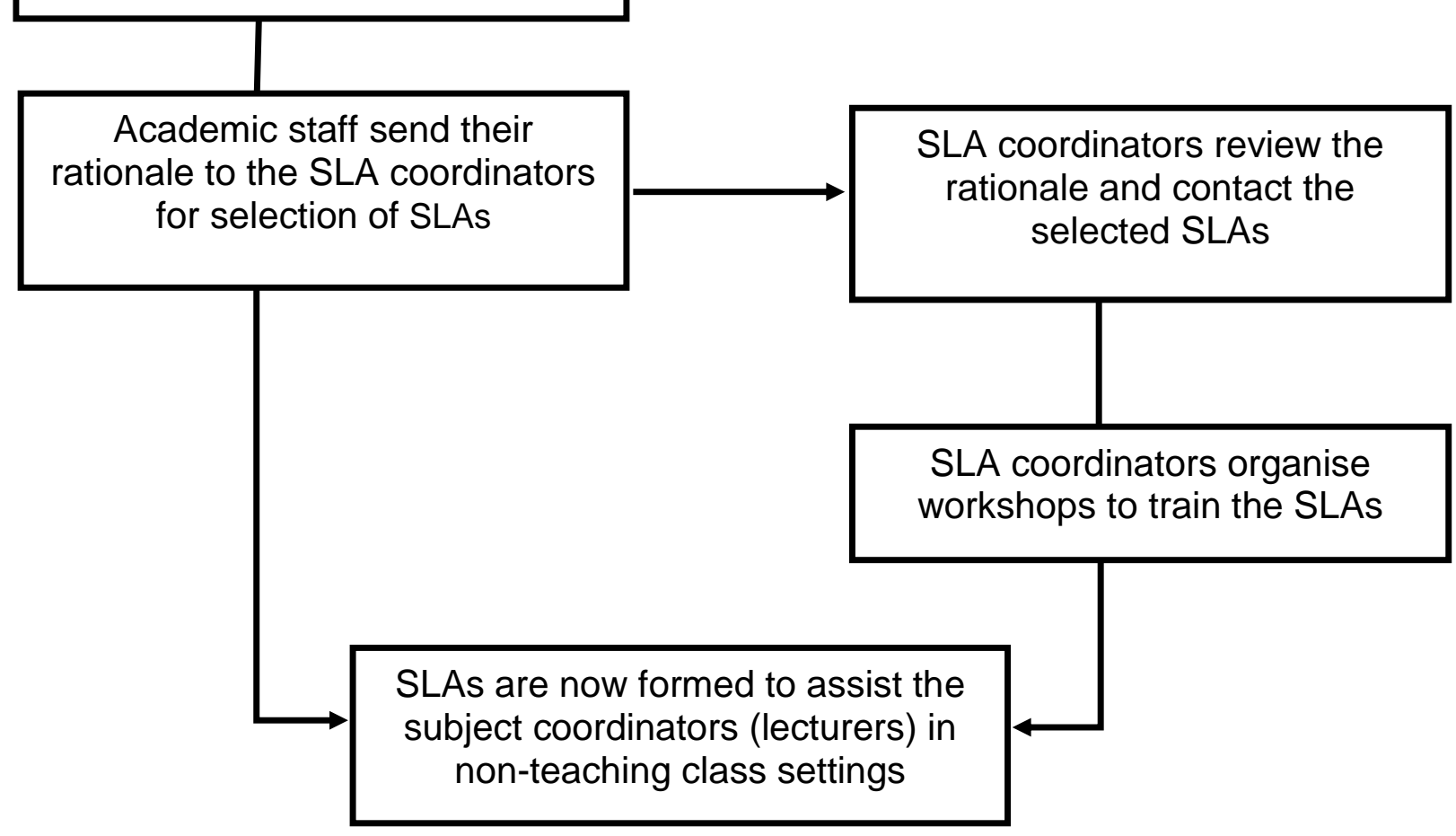

\section{Methodology}

In this paper, the main method used to collect data is based on action research design, primarily because this strategy's purpose is to solve a particular problem and to produce or improve guidelines for best practice (Denscombe, 2010, p.6). To this effect, surveys in the form of questionnaires have been used as the primary method of collecting data. The surveys were carried out at the end of the training workshops and also administered at the end of each semester to collect feedback from SLAs as well as students and lecturers who benefited from the SLA support. All four surveys have been designed by the SLA coordinators.

The first survey provided the SLAs with the opportunity to offer feedback on the workshops organised for their training and to make suggestions for improving future training sessions. The second survey, administered at the end of the semester, sought to collect the SLAs' 
views on their experience in their role. It was composed mainly of open-ended questions and focused on their preparedness for each seminar/lab/workshop they participated (in the presence of the lecturer), personal achievement in comparison with their experience before their new role, and any additional support required. The third survey intended to analyse the perception of students receiving SLA support and covered participant responses to five main criteria: namely, overall satisfaction with the SLA; clarity of the SLA's purpose in the class; consolidation of module's knowledge; study skills gained; and opinion of the SLA scheme in relation to their performance. This has been the most critical survey because it enabled the SLA coordinators to deduce whether SLAs behaved as facilitators or engaged in covert teaching. The first section of this particular survey comprised closed-ended questions while the remaining sections looked at open-ended questions. The final survey was designed for the lecturers who benefited from SLA support. This survey's aim was to investigate on a comparative level whether the lecturers viewed the SLAs as being prepared for the session and having achieved the skills required to earn the SLA certificate. The survey responses were then analysed by the SLA coordinators to summarise the main characteristics derived from the set of data collected. A deductive approach was also used to group the data and look for similarities and limitations which are discussed in later sections of this paper. This approach was chosen because the research was small in scale at this point of the SLA project.

While conducting the survey research, participants were informed of the purpose of the research so that they could make an informed judgment, and anonymity was preserved. At this early stage of the scheme, questionnaire surveys were a convenient method of data collection due to the manageable number of staff and students taking part in the scheme. In the future, as the number of participants grows, other methods such as online surveys or focus groups can be considered as means of collecting and sharing feedback. Focus groups would offer the possibility of collecting a large amount of data from one session and to obtain a range of opinions in detail (Mansell et al., 2004). SPSS (Statistical Package for the Social Sciences) as a research strategy can be potentially explored in the future. 


\section{Implementation process}

\section{Phase One}

The implementation process of the SLA scheme comprises different phases. The first stage consists of making the academic staff aware of the project and the SLA support they can use to enhance students' engagement in their classes. A mass e-mail is sent including the date of the scheduled workshop. During the workshop, members of the academic staff are informed of what an SLA scheme is and is not - i.e. namely it is not an initiative aimed at students with learning difficulties; teaching by students; a chance to cut down the lecturer-student contact; a means of creating dependency on SLAs; or an opportunity for students to chat about topics unrelated to their subject. These principles and aims are in alignment with the guidelines already in place since 2009 at Middlesex University Hendon Campus.

The advantages of the SLA scheme to the academic staff are elaborated during the workshop. Whilst 'the responsibility for supporting learners rests ultimately with teachers in the disciplines' (Bailey, 2010, p.1), the lecturers are encouraged to use SLA support to help enhance the independent learning approach of students in their class. According to Donelan (1999), a research into student-to-student support reveals that there are benefits gained from encouraging cooperative and participative learning through discussion. Independent reasoning and thinking skills are further enhanced (Capstick and Fleming, 2001) and the ability to apply abstract ideas are positively influenced within peer-led sessions (Lundeburg and Moch, 1995). The student experience is improved with SLA support and drop-outs are potentially reduced as evidenced by previous studies on student-to-student support schemes, which report the positive influence of PAL sessions on assessment marks (Coe et al., 1999). Moreover, the SLA scheme trains students in the basics of group work, which is a proven effect of student-to-student support schemes on the development of transferable skills (Price and Rust, 1995).

An additional argument which can potentially appeal to lecturers is how SLAs can alleviate the number of minor requests from students on the workload of lecturers. The minor requests consist of checking the attendance or answering a seminar question again, amongst other queries. Another key aspect of the SLA scheme is the opportunity it creates for lecturers to collect regular feedback on how the course content is being received by students within the class. 
Following the workshop, the lecturers interested in using an SLA's support in their classes are requested to send a brief rationale containing the names of two or three students who they consider to be ideal candidates for the role and to explain their choice(s). Owing to a limited budget for the SLA programme, the lecturers are also informed that not all members of the academic staff would be provided with an SLA. Hence, their rationale would be crucial in deciding the SLA allocation. The SLA coordinators and the Campus Director, who acted as an independent consultant, finalised the choice of the SLAs.

\section{Phase Two}

The second phase of the SLA scheme consists of contacting the selected SLAs and organising workshops to train them. Prior to organising the workshops, the following issues are considered:

- What should the training encompass?

- Who would do the training?

- Would other academic staff be willing to assist?

- When will the training take place?

- How would the training be evaluated?

Once the above demands were identified, different solutions were proposed. The selected solutions are explained in Table 2. 


\section{Table 2: Steps considered prior to Phase 2}

\begin{tabular}{|c|c|c|c|}
\hline & Proposed solutions & Rationale & Conflicting issues \\
\hline \multirow{6}{*}{$\begin{array}{l}\text { What should the } \\
\text { training } \\
\text { encompass? }\end{array}$} & $\begin{array}{l}\text { Training on 'what is an } \\
\text { SLA?' }\end{array}$ & $\begin{array}{l}\text { To clearly explain the role of the SLA as being a facilitator and to clear any } \\
\text { assumptions SLAs may have as being teachers. }\end{array}$ & \\
\hline & $\begin{array}{l}\text { Training on 'Learning } \\
\text { styles' }\end{array}$ & $\begin{array}{l}\text { To enlighten SLAs on the numerous approaches to learning they may } \\
\text { encounter in the classroom and how to adapt to the varying class } \\
\text { dynamics. }\end{array}$ & \\
\hline & $\begin{array}{l}\text { Training on 'Teaching } \\
\text { styles' }\end{array}$ & $\begin{array}{l}\text { To make sense of what is taught by the subject coordinator and develop } \\
\text { appropriate strategies to link the module contents' within relevant context } \\
\text { for the new students. }\end{array}$ & \\
\hline & $\begin{array}{l}\text { A workshop on 'How } \\
\text { does it feel to be a new } \\
\text { lecturer?' }\end{array}$ & $\begin{array}{l}\text { To share the fresh experience of a lecturer who has to develop effective } \\
\text { classroom management strategies. The aim was to inspire the SLAs in } \\
\text { their new role despite the challenges they may encounter. }\end{array}$ & \\
\hline & $\begin{array}{l}\text { Training on 'Diversity at } \\
\text { university: how to deal } \\
\text { with it?' }\end{array}$ & $\begin{array}{l}\text { To familiarise students with not just cultural diversity but also the different } \\
\text { schools of thought students will bring in the classroom and how the } \\
\text { preconceived knowledge they carry can either positively or negatively } \\
\text { affect their studies. }\end{array}$ & \\
\hline & An activities workshop & $\begin{array}{l}\text { To make students familiar with different group work settings and how to } \\
\text { facilitate learning in case scenarios where some students take a laid back } \\
\text { attitude, whilst others are a step ahead. }\end{array}$ & \\
\hline $\begin{array}{l}\text { Who would do the } \\
\text { training? }\end{array}$ & $\begin{array}{l}\text { SLA coordinators with at } \\
\text { least a PGCertHE }\end{array}$ & Their experience with teaching and their understanding of the SLA scheme. & \\
\hline $\begin{array}{l}\text { Involvement of } \\
\text { other academic } \\
\text { staff }\end{array}$ & A few volunteers & $\begin{array}{l}\text { To relieve the workload of the SLA coordinators who are also additionally } \\
\text { involved in teaching. }\end{array}$ & $\begin{array}{l}\text { Timetable clashes meant } \\
\text { accommodating their schedule } \\
\text { with that of the SLAs was } \\
\text { complex. }\end{array}$ \\
\hline When? & $\begin{array}{l}\text { Ideally before the first } \\
\text { learning week }\end{array}$ & $\begin{array}{l}\text { To familiarise SLAs with their role in due time prior to their first SLA } \\
\text { sessions. }\end{array}$ & Timetable clashes. \\
\hline $\begin{array}{l}\text { Evaluation of } \\
\text { training }\end{array}$ & Questionnaires & $\begin{array}{l}\text { To obtain feedback from both lecturers and SLAs to improve future } \\
\text { schemes. To evaluate the usefulness of the sessions, the impact on SLAs' } \\
\text { formation and their confidence level as well as identify whether they would } \\
\text { recommend the scheme to others. The feedback also included the scope } \\
\text { for individual comments and suggestions. }\end{array}$ & \\
\hline
\end{tabular}


The basis behind training SLAs on learning and teaching styles draws on the logic that students' learning is highly influenced by their previous learning experiences. SLAs ought to be familiar with the different case scenarios they are likely to come across in a class setting. Learning style is described as a consistent way in which individuals perceive, conceptualise, organise and recall information (Ellis, 1985). This conceptualisation of learning suggests that students' approach to acquiring knowledge is a subjective experience. Therefore, when facilitating seminars/labs/workshops, SLAs will most likely come across a range of learning styles which they may not necessarily be familiar with but which they are expected to be aware of in order to be effectively prepared to undertake their role. Hence, the aim of mentoring SLAs on learning styles through these workshops is to help them understand and internalise abstract educational ideas on a practical level.

However, it is important to highlight that SLAs do not receive any formal pedagogical or instructional training per se; rather, they are trained to act as facilitators and to motivate students to help each other learn while learning themselves (Mackey et al., 2010). Bandura's social learning theory encourages the practice of student-to-student support: learning occurs when an individual acquires knowledge by observing another person doing it (Bandura, 1977). There is abundant research literature available showing that peers can play an important role in enhancing a student's learning (Kuh et al., 2005; Pascarella and Terenzini, 2005). More relevantly, students can observe an individual's behaviour, recollect information regarding that individual's performance, and then guide their own future behaviours accordingly. Mackey et al. (2010, p.13) argue that 'while vicarious learning has been found to increase observing students' self-efficacy, the person modelling the behaviour is also affected by the same experience'. Feedback from one of the SLAs on the MUMBC campus, as a matter of fact, reveals that the SLA 'started using the same method [used during SLA sessions] to help [him/her] understand [his/her] own modules better'.

Further research by Braaksma et al. (2002) on observational learning and the effects of model-observer similarity, suggests that students who observed peer models were both more independent and effective at learning and in performing better in comparison to those who observed teacher models. Using the social learning theory as a point of illustration, the SLAs are informed of all the benefits to their own learning and the positive influence of their role on other students' learning. Vygotsky (1978) argues that students 
are more likely to learn when they are in an environment that facilitates thinking and discussing ideas together, and they are also more likely to analytically solve problems without a teacher's constant intervention. In order to limit the dependence of students upon teachers in their engagement with the curriculum, especially at the entry level, more opportunities ought to be available for them to learn with and from their peers. 'Providing a structured environment for students to collaborate on a given task with sufficient facilitation [...] allow[s] learning to happen' (Sultan et al., 2013, p.61). According to Vygotsky (1978), this forms the basis of the peer collaborative learning strategy, embedded in social constructivist values. It facilitates 'the cognitive development of students' where 'learning is constructed in an interactive social context' (Jacobs et al., 2008, p.6).

\section{Limitations of the SLA implementation structure}

Although the overall feedback on the organised training workshops collected from both the academic staff and the SLAs revealed an enjoyable and productive experience as outcome, the SLA coordinators faced numerous challenges in the planning and running of the SLA scheme. The timetable clashes meant it was complex to reach ideal slots which would be convenient for the training of SLAs and which did not coincide with their own respective learning timetable. This resulted in the duplication of some workshops. A student who was selected for the SLA role had to drop out because he could not assist the lecturer's class as it was in conflict with his own timetable. The six different workshops were run by the two SLA coordinators who were also lecturers and engaged in teaching. The lecturers therefore already had a busy timetable which caused further delay in organising the workshops.

Another limitation of the scheme was the failure of the students who used an SLA's support within a class to distinguish between the SLA's role and that of the lecturer. The feedback from the class students who experienced and benefited from the SLA support revealed that the students were still unclear about the role of the SLA as being a facilitator and not a teacher. For example, for the general comment section on the questionnaire, a considerable proportion requested one-to-one sessions with the SLA. The authors of this paper consider this as a limitation because it appears that the role of the SLA within the class may have gone beyond the conditions initially set when forming them. SLAs are not 
formally trained instructors. Their role, therefore, ought to be limited to facilitating student engagement within a class rather than trying to take an overly proactive initiative to covertly imitate the lecturer's role.

Another notable challenge once the SLA scheme was operational has been the timetable clashes of the lecturers who had to meet the SLAs to coordinate their role prior to the seminar sessions. One lecturer noted that although the SLA initiative has been helpful to his teaching, 'meeting the SLA prior to the seminar session was not always easy due to SLA timetable constraints and [his/her] own availability. But somehow we managed'.

\section{Recommendations for future implementation}

Measures should be taken to advertise the SLA scheme to the members of academic staff prior to the semester break. In this way, the workshops for academic staff can be organised before the end of the semester. Lecturers need to be encouraged to send their rationale before the term ends so that the selection of SLAs is carried out early. The aim is to ultimately train the SLAs ideally before the first learning week of each term so as not to delay their first session. From what is observed in Figure 1, if the hierarchy of the phases is not respected or one step is delayed, the final outcome, which is the effectiveness of an SLA's role in facilitating the lecturer's class, is affected.

Moreover, the SLA coordinators advise lecturers to take into consideration any changes in the syllabus before using an SLA's support in their class. The SLA is a student who is familiar with the module and who is able to share his/her experience so as to enhance the academic development of the students in the class. Nonetheless, if the syllabus is modified, SLAs would not be acquainted with all the content of the module. To the question addressed to lecturers on the questionnaire about the additional support which could be provided to an SLA, one lecturer recommended to 'allow [the SLA] in lectures so that they will have better coordination during seminars'. As an action to this feedback, the SLA coordinators would suggest to lecturers that before they consider delegating more responsibilities to the SLAs, who are facilitators in non-teaching classroom settings, they need to methodically learn the ropes of the SLA scheme, as well as the hierarchy of steps involved in implementing the process, and thoroughly understand the role of the SLA. The 
downside as reported by a lecturer who widely uses SLA support is that 'you can't complain when the burden becomes quite heavy' (Fletcher, cited University of Glasgow Peer Assisted Learning, 2005, p.10).

Academic staff who benefited from the SLA support range from the departments of Law, Information Technology and Business School. One response suggests that it has been a 'very positive experience. The SLA scheme has proven to be very beneficial especially in the $[. .$.$] department where there are many [...] students'. Another lecturer further$ commented on how the SLA 'initiative has benefited [his/her] teaching. [He/she] felt that the presence of the SLA in [his/her] class had a positive impact on [the] students as they would see the SLA as someone who 'has been there and done that'. The SLA's mere presence was a motivating factor to the student'. Based on the positive responses of the lecturers who benefited from the SLA support, the SLA coordinators seek to expand the project further to other faculties in the future.

The authors of this paper additionally support continuing research aiming to examine "how to maximise the accessibility of [student-to-student support schemes] to teachers who struggle to find ways to implement evidence-based instruction amidst all of the other challenges they face' (McMaster et al., 2007, p.98). Upon reflection of the SLA scheme's implementation on the new campus and acknowledging the need to overcome the limitations identified, this reflective paper also recognises that the SLAs' experiences may be different from other peer learning assistants at other higher education institutions. Future research should extend the current study.

\section{Conclusion}

This paper is a reflection of the SLA scheme's implementation at MUMBC. The SLA initiative is based upon a structured approach whose ultimate goal is to create an effective and productive learning environment, whereby SLAs are formed to act successfully as facilitators who motivate student engagement and encourage independent thinking among their peers. The venture follows a hierarchy of steps. Proceeding in such an organised way has helped the authors of this paper to identify the lacunas of the scheme. Upon detecting these gaps in the SLA's operational mechanism, the SLA coordinators have proposed 
suggestions to overcome the obstacles and improve future schemes on the new higher education campus. With appropriate as well as structured administration and support of all the departments, the SLA scheme can eventually have a far-reaching impact on the strategy we adopt to support the students at MUMBC, and can effectively facilitate their learning experience and engagement with their studies. The SLA coordinators intend to expand the SLA scheme to other departments, namely to the International Foundation Programme, Business Management, Psychology, Accounting and Finance, and Mathematics and Statistics. One module, Business Law, which is part of the Accounting and Finance programme, has been identified as a unit where accounting students are facing difficulties in coping with the unexpected legal component of the programme. The new law content of the module has come across as intimidating to the accounting students. The authors of this paper seek to elaborate on how the SLA scheme can benefit students of these types of unconventional modules of particular programmes in their next publications.

\section{References}

Ahrens, R., George, B., Henderson, A., Marhinin, N., Power, D., Rae, M., Watters, J.J. and Ginns, I.S. (1996) 'Students helping students: Peer Assisted Study Sessions for students enrolled in a science content subject', Paper presented at the 2nd State Conference of HERDSA Inc. University of Southern Queensland, Toowoomba, Queensland, Australia 13-14 April.

Arendale, D. (1994) 'Understanding the supplemental instruction model', in Martin, D.C. and Arendale, D. (eds.), Supplemental instruction: increasing achievement and retention. San Francisco, CA: Jossey-Bass Publishers, pp. 11-21.

AUSSE (2010) 'International students' engagement with effective educational practices: a cross-national comparison', Australasian Survey of Student Engagement; Research Briefing, Volume 5, January 2010 [Online]. Available at: http://www.acer.edu.au/ausse/reports (Accessed: 22 April 2014). 
Bailey, R. (2010) 'The role and efficacy of generic learning and study support: what is the experience and perspective of academic staff?', Journal of Learning Development in Higher Education, Issue 2, February, pp. 1-14.

Bandura, A. (1977) 'Self-efficacy: toward a unifying theory of behavioral change', Psychological Review, 84(2), pp. 191-215.

Barrett, M., Sutcliffe, P. and Smith, B. (1994) 'Students as mentors: the case of management education', Proceedings of the Conference of the Australian and New Zealand Academy of Management. Wellington, Australia: Australian and New Zealand Academy of Management.

Beasley, C.J. (1997) 'Students as teachers: the benefits of peer tutoring', in Pospisil, R. and Willcoxson, L. (eds.) Proceedings of the 6th Annual Teaching Learning Forum. Perth, Australia, February. Perth: Murdoch University, pp. 21-30.

Braaksma, M.A.H, Rijlaarsdam G. and Van den Bergh, H. (2002) 'Observational learning and the effects of model-observer similarity', Journal of Educational Psychology, 94(2), pp. 405-415.

Boud, D., Cohen, J. and Sampson, J. (2001) Peer learning in higher education. London: Kogan Page.

Capstick, S. and Fleming, H. (2001) 'Peer Assisted Learning in an undergraduate hospitality course: second year students supporting first year students in group learning', Journal of Hospitality, Leisure, Sport and Tourism Education, 1(1), pp. 6975.

Coe, E., McDougall, A. and McKeown, N. (1999) 'Is Peer-Assisted Learning of benefit to undergraduate chemists?', University Chemistry Education, 3(2), pp. 72-75 [Online]. Available at: http://www.rsc.org/pdf/uchemed/papers/1999/32 coe.pdf (Accessed: 11 December 2013). 
Denscombe M. (2010) Good research guide: for small-scale social research projects. $4^{\text {th }}$ edn. Berkshire, GBR: Open University Press.

Donelan, M. (1999) 'SI Mentors: the real winners', National Conference on Supplemental Instruction. University of Missouri Kansas City, USA 20-22 May.

Ellis, R. (1985) Understanding second language acquisition. Oxford: Oxford University Press.

Galbraith, J. and Winterbottom, M. (2011) 'Peer-tutoring: What's in it for the tutor?', Educational Studies, 37(3), pp. 321-332.

Glynn, L.G., MacFarlane, A., Kelly, M., Cantillon, P. and Murphy, A.W. (2006) 'Helping each other to learn - a process evaluation of peer assisted learning', BMC Medical Education, 6(18) [Online]. Available at: http://www.ncbi.nlm.nih.gov/pmc/articles/PMC1458341/ (Accessed: 25 April 2014).

Ibrahim, M.D.B. and Aaijaz, N. (2011) 'Dynamics of peer-assisted learning and teaching at an entrepreneurial university: an experience to share', International Journal of Humanities and Social Science, 1(12), pp. 93-99.

Jacobs, G., Hurley, M. and Unite, C. (2008) 'How learning theory creates a foundation for SI leader training', Australasian Journal of Peer Learning, 1(1), pp. 6-12.

Kift, S. (2009) 'Articulating a transition pedagogy to scaffold and to enhance the first year learning experience in Australian higher education; Final Report for ALTC Senior Fellowship Program', Australian Learning and Teaching Council [Online]. Available at: http://www.olt.gov.au/resource-first-year-learning-experience-kift-2009 (Accessed: 22 April 2014).

Kuh, G.D. (2003) 'What we're learning about student engagement from NSSE', Change, 35(2), pp. 24-32. 
Kuh, G.D. (2008) High-impact educational practices: what they are, who has access to them, and why they matter. Washington: Association of American Colleges and Universities.

Kuh, G.D., Kinzie, J., Schuh, J.H., Whitt, E.J. and Associates (2005) Student success in college: creating conditions that matter. San Francisco, CA: Jossey-Bass.

Lillis, T. (2001) Student writing: access, regulation and desire. London: Routledge.

Loh, H. (1993) 'Peer Assisted Study Sessions in anatomy for nursing students', Proceedings of the Conference Peer Tutoring: Learning by Teaching. Auckland, New Zealand 19-21 August. New Zealand: The University of Auckland, pp. 193201.

Lundeburg, M. and Moch, S. (1995) 'Influence of social interaction on cognition in science', Journal of Higher Education, 60(3), pp. 312-335.

Mackay, T., Kamphoff, C. and Armstrong, J. (2010) 'Perceptions of participants involved in peer assisted learning in a professional athletic training education program', Athletic Training Educational Journal, 5(1), pp. 12-21.

Mansell, I., Bennett, G., Northway, R., Mead, D. and Moseley, L. (2004) 'The learning curve: the advantages and disadvantages in the use of focus groups as a method of data collection', Nurse Researcher, 11(4), pp. 79-88.

McMaster, K., Fuchs, D. and Fuchs, L.S. (2007) 'Promises and limitations of peer-assisted learning strategies in reading', Learning Disabilities: A Contemporary Journal, 5(2), pp. 97-112.

Parr, J.M. and Townsend, M.A.R. (2002) 'Environments, processes and mechanisms in peer learning', International Journal of Educational Research, 37(5), pp. 403-423.

Pascarella, E.T. and Terenzini, P.T. (2005) How college affects students: a third decade of research. San Francisco, CA: Jossey-Bass. 
Price, M. and Rust C. (1995) 'Laying firm foundation: the long term benefits of Supplemental Instruction for students in large introductory courses', Innovations in Education and Training International, 32(2), pp. 123-130.

Sultan, F.K.P.D., Narayansany, K.S., Kee, H.L., Kuan, C.H. and Manickam, M.K.P. (2013) 'Helping students with difficult first year subjects through the PASS Program', Journal of Peer Learning, 6(1), pp. 59-75.

Stout, M.L. and McDaniel, A. (2006) 'Benefits to supplemental instruction leaders', New Directions for Teaching and Learning, 106, pp. 55-62.

Tinto, V. (1987) Leaving college: rethinking the causes and cures of student attrition. Chicago: University of Chicago Press.

University of Glasgow (2005) Peer Assisted Learning (PAL) Co-ordinators Pack. University of Glasgow [Online]. Available at: http://www.gla.ac.uk/media/media 9269 en.pdf (Accessed: 25 June 2014).

Van der Meer, J. and Scott, C. (2009) 'Students' experiences and perceptions of Peer Assisted Study Sessions: towards ongoing improvement', Journal of Peer Learning, 2(1), pp. 3-22.

Vygotsky, L.S. (1978) Mind in society: the development of higher mental processes. Cambridge, MA: Harvard University.

\section{Author details}

B.K. Ashley Hoolash (B.Hoolash@mdx.ac.mu) is a Lecturer in Mathematics and Statistics at Middlesex University, Mauritius Branch Campus. He holds a PGCertHE and is a Fellow at the Higher Education Academy (FHEA), as well as a Fellow at the Institute of Mathematics and its Applications (FIMA). He is also a Chartered Mathematician (CMath). 
Adeelah Kodabux (A.Kodabux@mdx.ac.mu) is the Head of the Learner Development Unit and an Associate Lecturer at Middlesex University, Mauritius Branch Campus. She is one of the academic staff responsible for overseeing the running of the Student Learning Assistant (SLA) and Graduate Teaching Assistant (GTA) schemes. 